\title{
Prevalence of aortic root dilation in the Ehlers- Danlos syndrome
}

Richard J. Wenstrup, $M D^{1}$, Richard A. Meyer, $M D^{2}$, Jennifer S. Lyle, $B S^{1}$, Leah Hoechstetter, $M S^{1}$, Peter S. Rose, $M D^{3}$, Howard P. Levy, $M^{3}$, and Claire A. Francomano, $M D^{3}$

\begin{abstract}
Purpose: To determine the prevalence of proximal aortic abnormalities in patients with Ehlers-Danlos syndrome (EDS). Methods: In a prospective cohort study, aortic measurements by two-dimensional echocardiography were performed on consecutive EDS patients. Results: Twenty-eight percent (20 of 71) had aortic root dilation (ARD) (> +2 SD above population based norms). Fourteen of 42 individuals with the classical form of EDS (types I/II) and 6 of 29 individuals with the hypermobile form (type III) had ARD, with no gender differences. Conclusion: ARD is a common finding in EDS. Longitudinal studies are indicated to determine progression of ARD and its clinical significance. Genet Med 2002:4(3):112-117.
\end{abstract}

Key Words: Ehlers-Danlos, echocardiogram, aorta, aortic dilation

The Ehlers-Danlos syndromes (EDS) are a genetically, biochemically, and clinically diverse group of heritable connective tissue disorders having joint laxity and dermal features in common. ${ }^{1-3}$ Prior classifications of EDS have included up to 11 disorders. Recently a simplified classification came into use that takes into account increasing clinical experience and advances in our understanding of the molecular pathogenesis of these disorders. Table 1 provides the new Villefranche classification and its relationship to the most recent prior classification in 1988. ${ }^{2,4}$ Of these, the classical (EDS types I, II), hypermobile (EDS type III), and vascular (EDS type IV) types are by far the most common.

A variety of cardiovascular complications have been associated with EDS, including mitral valve prolapse, rupture of medium-sized arteries, varicose veins, easy bruising, dilation and/or rupture of the aortic sinus and rupture of the aorta. ${ }^{1,3,5-12}$ Pepin et al. ${ }^{13}$ recently reported the prevalence of cardiovascular complications in a large cohort of patients with vascular EDS; these primarily involve rupture or dissection of medium-sized arteries and the descending aorta. The prevalence of cardiovascular complications in the classical and hypermobile forms are unknown. We began to perform baseline echocardiographic evaluations on all EDS patients seen in our clinics after having identified a few cases of EDS with aortic root dilation, some of whom had complications. ${ }^{12}$ The data indicate that the prevalence of aortic root dilation in these two forms of EDS is higher than previously suspected and that longitudinal follow-up of a large cohort of EDS patients will be

From the ${ }^{1}$ Division of Human Genetics and ${ }^{2}$ Cardiology, Children's Hospital Medical Center, Cincinnati, Ohio; and ${ }^{3}$ National Human Genome Research Institute, NIH, Bethesda, Maryland.

Richard J. Wenstrup, MD, Division of Human Genetics, Children's Hospital Research Foundation, Cincinnati $\mathrm{OH}$ 45229-3039.

Received: November 16, 2001.

Accepted: February 26, 2002 necessary to determine whether or to what extent these patients are at risk for serious complications such as aortic rupture, valvular insufficiency, or dissection.

\section{MATERIALS AND METHODS}

\section{Clinical ascertainment}

All patients were seen in an outpatient setting between 1994 and 1999, either at Cincinnati Children's Hospital Medical Center (CHMC) or at the Clinical Center at the National Institute of Human Genome Research (NIHGR). The study was approved by the institutional review boards of both institutions, and informed consent was given for the study. At the time that this study was initiated in 1994, the subject population was limited to those who had the diagnosis of EhlersDanlos syndrome types I, II, or III. The diagnosis of EDS was made by a clinical geneticist (R.J.W., C.A.F.) on the basis of clinical criteria and the exclusion of other confounding diagnoses. During the course of the study, a new classification for the Ehlers-Danlos syndromes was proposed and adopted. ${ }^{4}$ From 1994 through 1997, the diagnosis of EDS subtypes was based on the clinical criteria for Ehlers-Danlos syndrome types I, II, and III, using the 1988 Berlin classification. ${ }^{2}$ The new classification had no effect on the study population; EDS types I and II were combined as classical EDS. EDS type III was in essence renamed as the hypermobile type. Patients entered into the study in 1998 to 1999 were diagnosed according to the criteria published with the new classification ${ }^{4}$ (Table 1). The diagnosis of the classical form required presence of joint laxity, hyperextensibility of skin, and thin atrophic scars. The dermis is fragile and is easily bruised. Family history had to have been consistent with new dominant mutation or autosomal dominant transmission in a pedigree. The diagnosis of the hypermobile form required the presence of generalized hypermobility of joints and soft, velvety skin. Individuals with this type have normal scarring, but may have stretchy skin. Nearly all 
Table 1

The Ehlers-Danlos syndromes

\begin{tabular}{|c|c|c|c|c|}
\hline $\begin{array}{l}\text { Villefranche } \\
\text { classification (1997) }\end{array}$ & Berlin classification (1988) & Clinical features & Inheritance $^{a}$ & Molecular defects \\
\hline Classical type & $\begin{array}{l}\text { I Gravis } \\
\text { II Mitis }\end{array}$ & $\begin{array}{l}\text { Soft, hyperextensible skin; easy } \\
\text { bruising; thin, atrophic scars; } \\
\text { hypermobile joints; varicose veins; } \\
\text { prematurity of affected newborns }\end{array}$ & $\mathrm{AD}$ & $\begin{array}{l}\text { Mutations in pro } \alpha 1(\mathrm{~V}) \text { or pro } \alpha 2(\mathrm{~V}) \\
\text { chains of type } \mathrm{V} \text { collagen }(\mathrm{COL} 5 \mathrm{~A} 1 \text {, } \\
\text { COL5A2) in some families }\end{array}$ \\
\hline Hypermobility type & III & $\begin{array}{l}\text { Soft skin; large and small joint } \\
\text { hypermobility }\end{array}$ & $\mathrm{AD}$ & Not known \\
\hline Vascular type & IV Arterial-ecchymotic & $\begin{array}{l}\text { Thin, translucent skin with visible } \\
\text { veins; easy bruising; absence of skin } \\
\text { and joint extensibility; arterial, } \\
\text { bowel, and uterine rupture }\end{array}$ & $\mathrm{AD}$ & $\begin{array}{l}\text { Mutations in COL3A1; abnormal type III } \\
\text { collagen synthesis, secretion, or } \\
\text { structure }\end{array}$ \\
\hline Kyphoscoliosis type & VI & $\begin{array}{l}\text { Soft skin; muscle hypotonia; scoliosis: } \\
\text { joint laxity; hyperextensible skin }\end{array}$ & $\mathrm{AR}$ & $\begin{array}{l}\text { Lysyl hydroxylase deficiency, mutations in } \\
\text { PLOD gene }\end{array}$ \\
\hline Arthrochalasia type & $\begin{array}{l}\text { VIIA, VIIB Arthrochalasia } \\
\text { multiplex }\end{array}$ & $\begin{array}{l}\text { Congenital hip dislocation; severe } \\
\text { joint hypermobility; soft skin with } \\
\text { or without abnormal scarring }\end{array}$ & $\mathrm{AD}$ & $\begin{array}{l}\text { Deletion of exons from type I collagen } \\
\text { genes that encode the amino-terminal } \\
\text { propeptide cleavage site of COL1A1 } \\
\text { (type A) or COL1A2 (type B) }\end{array}$ \\
\hline Dermatosporaxis type & VIIC & $\begin{array}{l}\text { Severe skin fragility; sagging, } \\
\text { redundant skin }\end{array}$ & $\begin{array}{l}\text { Recessive mutations in type } \\
\text { I collagen N-peptidase }\end{array}$ & \\
\hline
\end{tabular}

${ }^{a} \mathrm{AD}$, autosomal dominant; $\mathrm{AR}$, autosomal recessive.

${ }^{b}$ Includes rare forms (types V, VIII, and X) from the 1988 Berlin classification that have only been described in a few families.

patients with the hypermobile form had a positive family history consistent with autosomal dominant inheritance.

The diagnosis of the classical form of EDS is usually straightforward. However, the classical and hypermobile forms of EDS have overlapping clinical features with other forms of EDS or other heritable connective tissue disorders that can occasionally make the specific diagnosis more difficult. For some study subjects, the diagnosis of the classical or hypermobile forms of EDS was made only after additional clinical evaluations or laboratory testing, including electrophoretic analysis of type III collagen chains to exclude the vascular form, ${ }^{14}$ the kyphoscoliosis form ${ }^{15,16}$ or the arthrochalasia forms of EDS. ${ }^{4}$ Some individuals with the hypermobile form who had associated pectus excavatum, scoliosis, or severe myopia were evaluated for Marfan syndrome and were included only if they had dermal features of hypermobile EDS and if the Marfan syndrome was clinically excluded. ${ }^{17}$ There is no diagnostic test for the hypermobile forms of EDS, as its molecular basis is not known.

\section{Echocardiography}

Complete echocardiograms were performed by experienced technologists according to the recommendations of the American Society of Echocardiography ${ }^{18}$ and were measured using the Digisonics ERS Echo View system. Offline two-dimensional measurements of the aortic root were made in end diastole. Parasternal long-axis views (Fig. 1) at four levels: (1) annulus (defined echocardiographically as the hinge points of the aortic cusps); (2) sinuses of Valsalva; (3) supra-aortic ridge (sinotubular junction), and (4) proximal ascending aorta were obtained following the method of Roman et al. ${ }^{18}$ Measurements were made perpendicu-

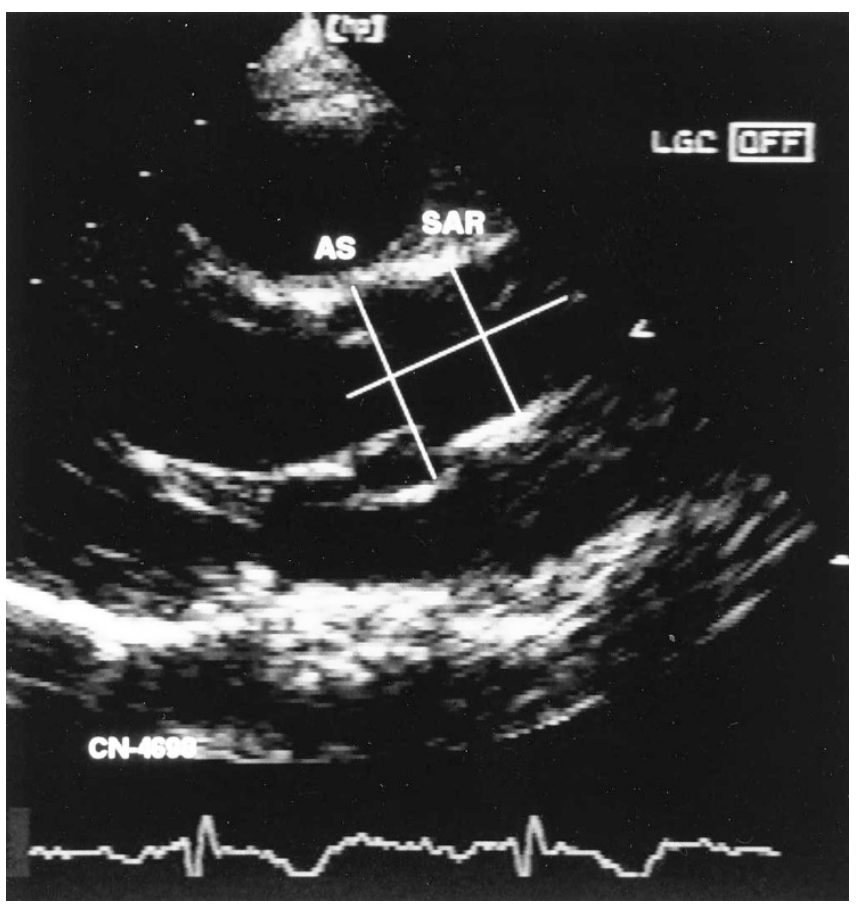

Fig. 1 Echocardiogram of the aorta from a young patient with a dilated aortic sinus in the two-dimensional parasternal long axis view. Measurements were made perpendicular to the long axis of the aorta at the level of the aortic sinus of Valsalva (AS) and supra-aortic ridge (SAR).

lar to the long axis of the aorta, using the leading edge technique and view showing the largest aortic diameters. Particular attention was paid to imaging the entire proximal portion of the aorta. Mea- 
surements were then plotted against published normal standards and indexed for body surface area (Fig. 2) according to age. ${ }^{18}$ Some patients who were measured in the earlier years of the study (1994-1995) did not have all four measurements, and measurements of the aortic sinus and/or the supra-aortic ridge were set as minimal requirements for inclusion into the study.

\section{RESULTS}

All patients with the classical and the hypermobile forms of EDS who received diagnostic evaluations at Cincinnati Chil- dren's Hospital (CHMC) or at the Clinical Center at the National Institute for Human Genome Research (NIHGR) from 1994 to 1999 also received baseline echocardiograms. Patients who had an abnormal measurement underwent repeat echocardiograms at 6- or 12-month intervals, depending on the degree of abnormality detected on the baseline study, although for the purpose of this study, only the echo measurements at the time of diagnosis were included in the analysis.

Seventy-one EDS patients qualified for the study based on a clinical diagnosis of either classical or hypermobile EDS (Table 2). The age at first echocardiogram ranged from 1 to 60 years.
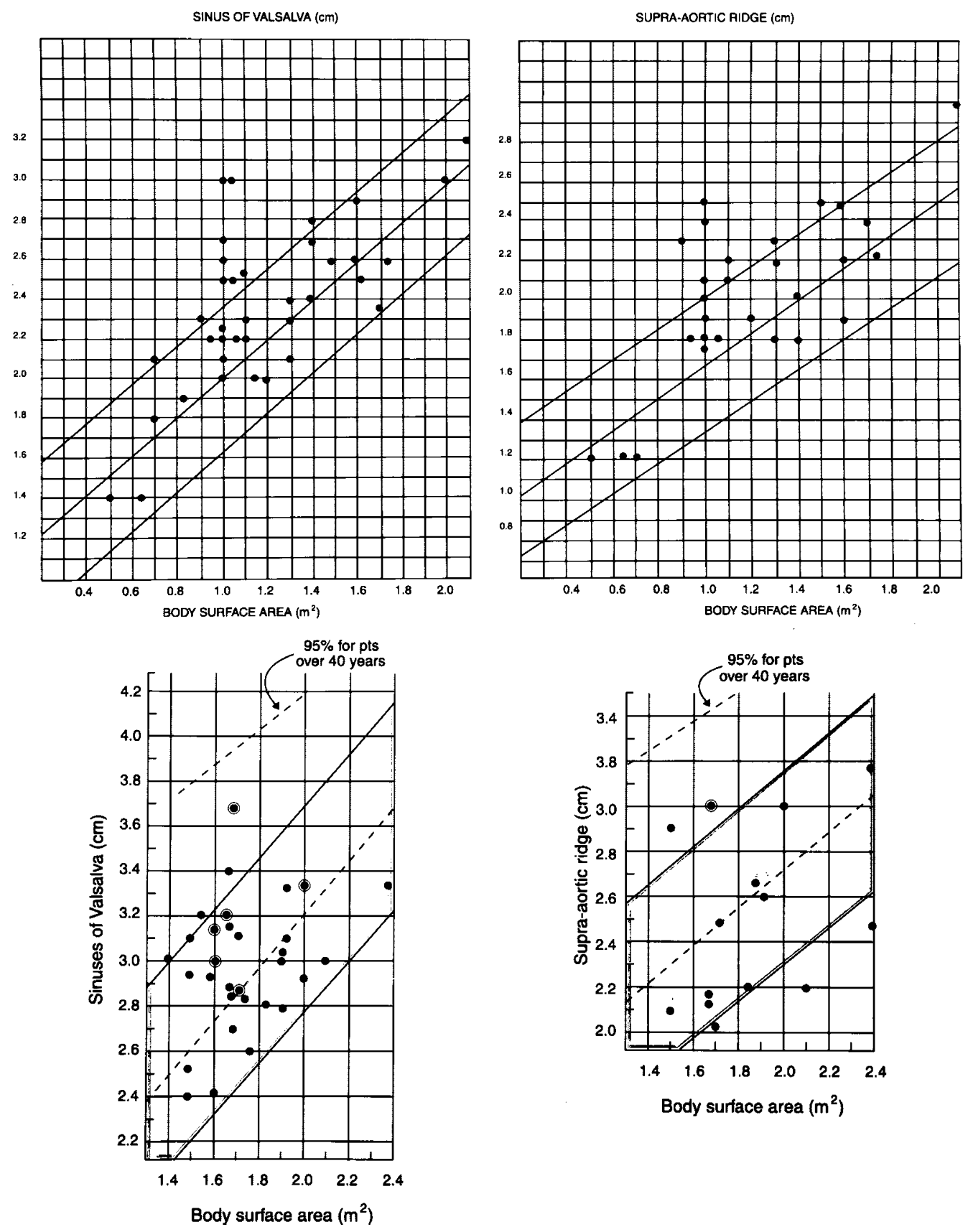

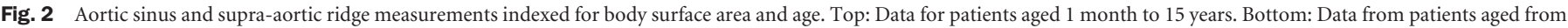
15 years to 40 years, including the $95 \%$ limits for patients over 40 years of age. ${ }^{18}$ Values within circles are from patients over 40 years of age. 
Table 2

Study subjects

\begin{tabular}{lccl}
\hline & CHMC & NIHGR & Total \\
\hline Subjects $(n)$ & 42 & 29 & 71 \\
Age, mean (range) & $14.4(1-49)$ & $29.6(6-60)$ & 20.6 \\
Female/male & $22 / 20$ & $21 / 8$ & $43 / 28$ \\
EDS subtype: classical/hypermobility & $20 / 22$ & $22 / 7$ & $42 / 29$ \\
\hline
\end{tabular}

The study population was $61 \%$ female; nearly all of the excess in female cases was contributed by the older NIHGR population. The average age at entry into the study was 23.4 years. Forty-two of 71 patients had classical EDS (types I/II), and the remaining patients had the hypermobile form (type III).

Twenty of 71 patients with EDS had at least an aortic sinus or supra-aortic ridge measurement greater than two standard deviations above the age and body surface area-adjusted mean as determined by previously described methods ${ }^{18}$ (Table 3 ). In some of the group over 40 years of age, only sinus measurements were available. Neither the age-adjusted height nor the age-adjusted body surface area deviated significantly from population norms (data not shown). The age at diagnosis of ARD ranged from 7 to 60 years. The prevalence of ARD was nearly identical in males and females. There was a trend toward higher prevalence of ARD in classical EDS than in hypermobile EDS (33\% and $17 \%$ respectively), but the results did not achieve statistical significance.

Four EDS patients were excluded because they were ascertained on the basis of aortic abnormalities. One of these was previously reported (Patient 5). ${ }^{12}$ Two of these had originally been given the diagnosis of Marfan syndrome elsewhere on the basis of joint laxity and aortic disease; one of these two had suffered a proximal aortic dissection and had undergone aortic replacement with a Teflon graft. If these patients were not excluded, the prevalence of ARD in this population would be $32 \%$ ( 23 of 75 ) instead of $28 \%$ ( 20 of 71 ).

The aortic sinus was by far the most commonly affected site. Of the 20 patients with ARD, 16 had dilation of the aortic sinus. Four had dilation at the supra-aortic ridge without dilation at the aortic sinus. None had dilation at the level of the aortic annulus. Two patients had dilation of the ascending aortic distal to the supra-aortic ridge. The high prevalence of ARD, at

Table 3

Percentage of EDS patients with ARD

\begin{tabular}{lccc}
\hline & CHMC & NIHGR & $\begin{array}{c}\text { Combined } \\
\text { total }\end{array}$ \\
\hline ARD total & $9 / 42(21 \%)$ & $11 / 29(34 \%)$ & $28 \%$ \\
$\begin{array}{l}\text { Age at initial ARD diagnosis, } \\
\text { mean (range) }\end{array}$ & $14.4 \mathrm{yr}(7-21)$ & $33.0 \mathrm{yr}(9-60)$ & $23.4 \mathrm{yr}$ \\
$\begin{array}{l}\text { Female/male } \\
\begin{array}{l}\text { EDS subtype: } \\
\text { classical/hypermobility }\end{array}\end{array}$ & $22 \% / 20 \%$ & $28 \% / 50 \%$ & $27 \% / 28 \%$ \\
\hline
\end{tabular}

least in the aortic sinus measurements of younger patients, appears to be part of a general upward shift in aortic size rather than due to a subset of easily distinguishable outliers (Fig. 3, top). The general upward shift was not noticeable in measurements of the supra-aortic ridge, where far fewer abnormal measurements were made (Fig. 3, bottom).

\section{DISCUSSION}

Echocardiographic evaluation of patients who had either classical or hypermobile EDS and who were seen consecutively at two clinical genetics centers demonstrated an unexpectedly high prevalence of aortic dilation in the proximal aorta, particularly in the group under 15 years of age. There were no differences in ARD rates by sex. The overall prevalence of ARD was

\section{Aortic Sinus Diameter \\ (Relative to Mean for Age and Body Mass Index)}
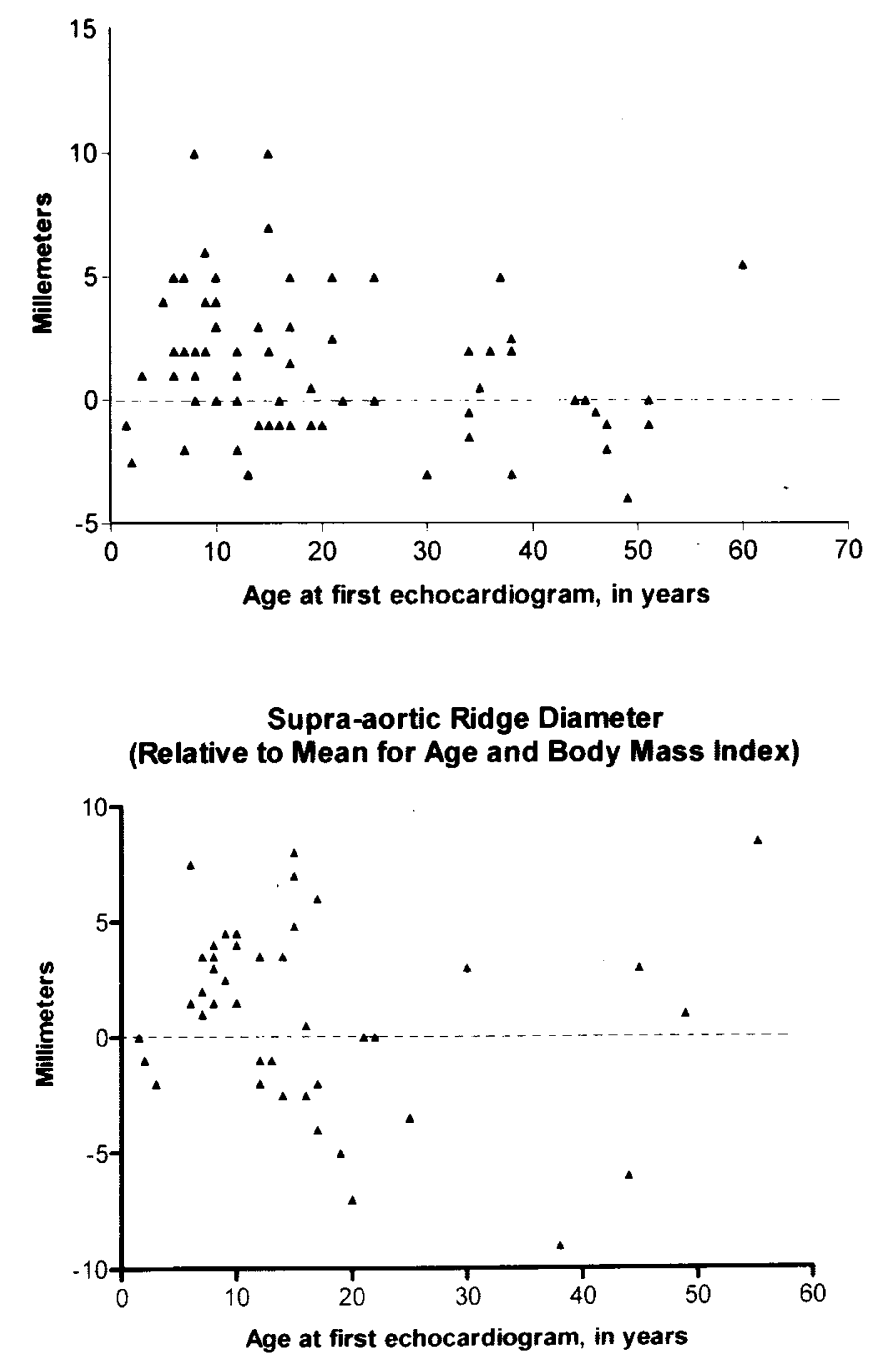

Fig. 3 The indexed aortic measurements of the aortic sinus (top) and supra-aortic ridge (bottom) above and below the mean value (0). The sinus measurements appear broadly shifted upward in the EDS populations, whereas it is not as evident in the supra-aortic ridge measurements. 
substantially higher in classical EDS (33\%) than in hypermobile EDS (17\%), but the two forms had an identical frequency in the larger, younger cohort of EDS patients seen at one center (CHMC). Relatively few patients with the hypermobile form were studied at NIHGR; none had ARD. A future study with a larger patient base might better determine the difference in the ARD prevalence rates between different forms of EDS. Surprisingly, ARD was found more frequently than mitral valve prolapse, which has previously been identified as a cardiac complication of EDS. ${ }^{1,3}$

In the absence of complete ascertainment of all known patients with EDS within a defined geographical region, prevalence data using consecutive patients seen in two clinical centers in two geographic regions may be the best alternative. At the very least, the prevalence estimates included in this report should reflect the expected frequency of ARD among EDS patients in a typical outpatient setting. One of the two centers that participated in this study (Children's Hospital Medical Center, Cincinnati) was a combined genetics-cardiology clinic specializing in heritable connective tissue disorders. In this setting, an important potential source of ascertainment bias might be patients who were identified on the basis of prior or suspected cardiovascular disease, which would be expected to enrich the EDS population for those individuals with ARD. Therefore, we calculated ARD prevalence both including or excluding those individuals. The prevalence rates of $32 \%$ and $27 \%$, which are the result of including or excluding patients identified on the basis of their aortic abnormalities, respectively, may represent upper and lower estimates of ARD in Ehlers-Danlos syndrome patients with the classical or hypermobile forms (types I, II, and III). These data represent the first prevalence rates for this complication in the Ehlers-Danlos syndrome. In contrast, the major aortic complications of the vascular form of EDS (type IV)_-dissection and rupture-are likely not preceded by vessel dilation, and usually occur in the descending rather than the proximal aorta. ${ }^{14}$ Our experience indicates that the onset of ARD in EDS can be observed in early childhood, but the crosssectional data elicited by the study design do not provide information on the progression of ARD in this group of patients. Furthermore, the study size, cross-sectional design, and exclusion of patients with predetermined aortic disease limited our ability to determine the percentage of patients with EDS that have serious complications of ARD such as valvular insufficiency, aortic rupture or dissection, or preemptive replacement with an aortic graft.

Our study size is particularly limited in the older age group. It appears that significant ARD is present in the young but less so in young or older adults. A possible explanation for this is that the aorta in young patients is more distensible and tends to normalize as it stiffens with age. Measurement error in younger children has a higher impact: 1 - or 2-mm measurement discrepancies in a small structure may result in a larger error; however, careful measurement technique over time should cancel or minimize that error in the same patient. A longitudinal study with a larger patient base will help clarify these remaining issues.
Overall, the frequency of ARD is substantially lower in EDS than what has been reported in the Marfan syndrome, ${ }^{17,19,20}$ in which up to $80 \%$ of individuals have abnormal aortic measurements by two-dimensional echocardiogram. Some of this difference may be related to the fact that aortic enlargement represents a major diagnostic criterion for the Marfan syndrome but not EDS.

Information about rates of progression and complication rate for ARD is incomplete even for the Marfan syndrome. In a study of 25 children with Marfan syndrome, Geva and coworkers $^{19}$ found that $80 \%$ had increased aortic root diameter. After follow-up of 5 years, one fourth of these had an increase in aortic root diameter out of proportion to change in body mass; those diagnosed before 10 years of age were more likely to have significant progression in aortic root diameter. The actual percentage of Marfan patients with ARD who progress to aortic valvular insufficiency, rupture, dissection, or preemptive repair is not precisely known. Hence, for patients with EDS, cross-sectional data indicates that further longitudinal studies are necessary to determine onset of ARD, the likelihood of progression of ARD relative to increases in body size and agedependent-norms, and whether these patients are at risk for the above complications.

It is possible that EDS patients with ARD have a specific molecular defect that renders them susceptible to aortic disease. There has been recent progress in understanding the molecular basis of classical EDS (formerly types I and II). Between $40 \%$ and $50 \%$ of individuals with classical EDS have abnormalities in one of two genes that code for type $\mathrm{V}$ collagen (COL5A1 and COL5A2). ${ }^{21-27}$ Routine laboratory diagnosis of this form of EDS is still not practical, and segregation analysis of some families with classical EDS have excluded COL5A1 and COL5A2 in some. ${ }^{24,28}$ The genetic basis of the hypermobile form of EDS (type III) is unknown. It may be that the current clinical classification of EDS will be modified with the advent of a molecular nosology and improvement in laboratory diagnosis and that risk for ARD may eventually be limited to individuals with specific gene defects.

In conclusion, our data indicate that aortic dimensions, at least at the aortic sinus (Figs. 2 and 3), are shifted broadly upward in our EDS populations, which is more consistent with a general effect on connective tissue biomechanics than with a model that is based on a subset of outliers having a common molecular defect. Therefore, at present, we think that clinicians should consider evaluating for the presence, development, and progression of ARD in patients who have EDS diagnosed by current clinical criteria.

\section{Acknowledgments}

This project was funded by a grant from the Children's Heart Association.

\section{References}

1. Beighton P. The Ehlers-Danlos syndromes. In: Beighton P, editor. McKusick's heritable disorders of connective tissue. St. Louis: Mosby, 1992:189-251. 


\section{Aortic root dilation in EDS}

2. Beighton P, De Paepe A, Danks D, Finidori G, Gedde-Dahl T, Goodman R, Hall JG, Hollister DW, Horton W, McKusick VA. International nosology of heritable disorders of connective tissue, Berlin, 1986. Am J Med Genet 1988;29:581-594.

3. Steinmann B, Royce PM, Superti-Furga A. The Ehlers-Danlos syndrome. In: Royce PM, Steinmann B, editors. Connective tissue and its heritable disorders. NY: WileyLiss, 1993:351-408.

4. Beighton P, De Paepe A, Steinmann B, Tsipouras P, Wenstrup RJ. Ehlers-Danlos syndromes: revised nosology, Villefranche, 1997. Ehlers- Danlos National Foundation (USA) and Ehlers-Danlos Support Group (UK). Am J Med Genet 1998;77:31-37.

5. Lynch HT, Larsen AL, Wilson R, Magnuson CL. Ehlers-Danlos syndrome and "congenital” arteriovenous fistulae. A clinicopathologic study of a family. JAMA 1965; 194:1011-1014.

6. McKusick VA, Larsen AL, Wilson R. The Ehlers-Danlos syndrome and "congenital" arterio-venous fistulae, a clinicopathologic study of a family. In: Royce PM, Steinmann B, editors. Heritable disorders of connective tissue. St. Louis: Mosby, 1966:292-371.

7. Tucker DH, Miller DE, Jacoby WJ Jr. Ehlers-Danlos syndrome with sinus of Valsalva aneurysm and aortic insufficiency simulating rheumatic heart disease. Am J Med 1963;35:715-720.

8. Leier CV, Call TD, Fulkerson PK, Wooley CF. The spectrum of cardiac defects in the Ehlers-Danlos syndrome, types I and III. Ann Intern Med 1980;92:171-178.

9. Lichtenstein JR, McKusick VA. Ehlers-Danlos syndrome with aortic aneurysm. Birth Defects Orig Artic Ser 1975;11:340.

10. Serry C, Agomuoh OS, Goldin MD. Review of Ehlers-Danlos syndrome. Successful repair of rupture and dissection of abdominal aorta [review]. J Cardiovas Surg 1988; 29:530-534.

11. Hata R, Kurata S, Shinkai H. Existence of malfunctioning pro alpha2(I) collagen genes in a patient with a pro alpha 2(I)-chain-defective variant of Ehlers-Danlos syndrome. Eur J Biochem 1988;174:231-237.

12. Tiller GE, Cassidy SB, Wensel C, Wenstrup RJ. Aortic root dilatation in Ehlers-Danlos syndrome types I, II, and III. A report of five cases. Clin Genet 1998;53:460-465.

13. Pepin M, Schwarze U, Superti-Furga A, Byers PH. Clinical and genetic features of Ehlers-Danlos syndrome type IV, the vascular type. NEngl J Med 2000;342:673-680.

14. Byers PH. Ehlers-Danlos syndrome type IV: a genetic disorder in many guises. J Invest Dermatol 1995;105:311-313.

15. Steinmann B, Eyre DR, Shao P. Urinary pyridinoline cross-links in Ehlers-Danlos syndrome type VI [letter]. Am J Hum Genet 1995;57:1505-1508.

16. Pasquali M, Dembure PP, Still MJ, Elsas LJ. Urinary pyridinium cross-links: a noninvasive diagnostic test for Ehlers-Danlos syndrome type VI [letter]. N Engl J Med 1994;331:132-133.
17. De Paepe A, Devereux RB, Dietz HC, Hennekam RC, Pyeritz RE. Revised diagnostic criteria for the Marfan syndrome. Am J Med Genet 1996;62:417-426.

18. Roman MJ, Devereux RB, Kramer-Fox R, O’Loughlin J. Two-dimensional echocardiographic aortic root dimensions in normal children and adults. Am J Cardiol 1989;64:507-512.

19. Geva T, Hegesh J, Frand M. The clinical course and echocardiographic features of Marfan's syndrome in childhood. Am J Dis Child 1987;141:1179-1182.

20. Rozendaal L, Groenink M, Naeff MS, Hennekam RC, Hart AA, van der Wall EE, Mulder BJ. Marfan syndrome in children and adolescents: an adjusted nomogram for screening aortic root dilatation. Heart 1998;79:69-72.

21. Burrows NP, Nicholls AC, Richards AJ, Luccarini C, Harrison JB, Yates JR, Pope FM. A point mutation in an intronic branch site results in aberrant splicing of COL5A1 and in Ehlers-Danlos syndrome type II in two British families. Am J Hum Genet 1998;63:390-398.

22. Richards AJ, Martin S, Nicholls AC, Harrison JB, Pope FM, Burrows NP. A single base mutation in COL5A2 causes Ehlers-Danlos syndrome type II. J Med Genet 1998;35:846-848.

23. Toriello HV, Glover TW, Takahara K, Byers PH, Miller DE, Higgins JV, Greenspan DS. A translocation interrupts the COL5Al gene in a patient with Ehlers-Danlos syndrome and hypomelanosis of Ito. Nat Genet 1996;13:361-365.

24. Wenstrup RJ, Langland GT, Willing MC, D'Souza VN, Cole WG. A splice-junction mutation in the region of proal $(\mathrm{V})$ chains results in the gravis form of the EhlersDanlos syndrome (type I). Hum Mol Genet 1996;5:1733-1736.

25. De Paepe A, Nuytinck L, Hausser I, Anton-Lamprecht I, Naeyaert J-M. Mutations in the COL5Al gene are causal in the Ehlers-Danlos syndromes I and II. Am J Hum Genet 1997;60:547-554.

26. Michalickova K, Susic M, Willing MC, Wenstrup RJ, Cole WG: Mutations of the alpha2(V) chain of type $\mathrm{V}$ collagen impair matrix assembly and produce EhlersDanlos syndrome type I. Hum Mol Genet 1998;7:249-255.

27. Wenstrup RJ, Florer JB, Willing MC, Giunta C, Steinmann B, Young F, Susic M, Cole WG. COL5A1 Haploinsufficiency is a common molecular mechanism underlying the classical form of EDS. Am J Hum Genet 2000;66:1766-1776.

28. Greenspan DS, Northrup H, Au KS, McAllister KA, Francomano CA, Wenstrup RJ, Marchuk DA, Kwiatkowski DJ. COL5A1: fine genetic mapping and exclusion as candidate gene in families with nail-patella syndrome, tuberous sclerosis 1, hereditary hemorrhagic telangiectasia, and Ehlers-Danlos Syndrome type II. Genomics 1995;25:737-739. 